\title{
New Co-Editor for Children Australia
}

I am delighted to be introducing myself as the recently appointed co-editor of Children Australia. Alongside Jennifer Lehmann and the team at Children Australia, I hope to support the journal's continued contribution to the important field of children, young people and their families. With my own beliefs heavily embedded in the value of information sharing and evidence-based practice, I subscribe to the journal's original objective of creating a forum that can 'open up discussion on policies and practices, to discuss innovations and the raising of standards' (Owen, 2005, p. 3). Within this role, I will endeavour to support academics and practitioners alike to share their knowledge and expertise of children's issues both locally and internationally.

This edition of the journal has quite a broad range of articles, commentaries and reviews, which we hope you will find interesting and informative. Among these, a number of articles attend to the issue of coping. Together, they offer engaging insight into the notion of coping and the strategies thought to be useful for individuals who are facing adversity, and who need to draw on their coping skills and mechanisms to thrive. I thought I might add to this discussion by sharing my recent observations of coping and resilience while working with flood-affected communities in the north-western region of Victoria. I will not go into the intricacies of coping mechanisms, styles and strategies, as I would rather leave that to the experts whose work is represented in this issue, but I will present a very brief summary of coping after a disaster.

Nine months have passed since the Victorian floods and the long arduous recovery process continues. For some, the recovery process is drawing to an end, but for many others it has barely begun. When accepting the role of flood recovery support worker, I imagined working with a significant number of people who were struggling to cope with the experiences of adversity and ongoing challenges they face. What I witnessed, however, was an amazing sense of individual and community resilience, determination and capacity to cope. There are many individuals, families and communities who are feeling confused, exhausted, angry, worried, stressed and all of the other normal responses people have to a disaster of this nature, but I was struck by the community's ability to cope with the emotional, financial, social and physical challenges placed on them.

The recovery process has focused primarily on restoring homes, businesses, infrastructure and economic stability; however, provisions for psychosocial support have also been made. Psychosocial resources have been directed to programs that promote mental health and minimise mental illness. This has included mental health education specifically targeted to disaster response and recovery, delivered by both Drs Rob Gordon and Sharon des Landes as well as beyondblue ${ }^{\mathrm{TM}}$. Flood recovery case workers have been employed to help relieve some of the daily stressors of recovery; as well as promote physical, mental and emotional health during the recovery process. Additional resources have been allocated to counselling services and community events aimed at strengthening community cohesion, cooperation and support have also been promoted. The psychosocial programs instituted to date have been primarily directed towards adults, with the more vulnerable members of the community (i.e., people who are elderly, have a disability or those with fewer socioeconomic opportunities to recover) most likely to engage with these services. It is particularly important, however, to ensure that children, as a potentially vulnerable group, are not overlooked in the frenzy of restoring infrastructure and financial stability.

Like adults, children and young people can experience posttraumatic stress disorder, depression, anxiety, complicated grief, substance abuse and other common psychological disorders in the wake of trauma (Caruana, 2010). Moreover, a humanitarian disaster of this sort can alter a young person's developmental and social trajectory, which can impact further on their psychological response. Depending on their stage of development, young people can present with separation anxiety, nightmares, guilt, avoidant behaviour, fear of recurrence, worry for the safety of self and others, increased risk-taking and aggressive behaviours and incoherent thinking (Caruana, 2010). In addition to their own experiences of trauma, young people are also predisposed to secondary trauma, which can be more devastating to them than the event itself. For example, young people's 
mental health can be significantly impacted upon if their parent's mental health is compromised or because of fractured family functioning (Caruana, 2010).

Family is a key factor in children's recovery. Families who furnish comfort, support and a sense of safety from within are more likely to be psychologically resilient (Caruana, 2010); whereas families who engage in 'transitional conflict' as a result of differing coping styles are less likely to achieve an early positive outcome (Landau, Mittal, \& Wieling, 2008). Moreover, children can be further affected by an increased incidence of domestic violence and child abuse following disasters, which carry the obvious consequences and concerns (Caruana, 2010; Cook, Watson, van Buynder, Robertson, \& Weinstein, 2008).

The individual psychosocial response to trauma varies depending on the individual and the event (Caruana, 2010), but the level of long- and short-term recovery efforts and relief services can affect the outcome. While most people experience some distress after a natural disaster, the majority of symptoms abate within a year. For a small percentage, however, distress and mental illness persist (Caruana, 2010). To promote mental health, practitioners are encouraged to normalise people's reactions, focus on coping competencies, encourage social engagement and advocate for a sense of hopefulness and control (MacDonald, 2009; Walsh, 2007). It is the role of the health professional to create a space in which community members feel safe to share their trauma, future plans and successes. It is my belief that practical assistance and financial support is appreciated, but what appears to be profoundly valued by community members is having their story witnessed and their efforts acknowledged and respected.

Of particular importance is the application of a multisystemic approach to recovery. Viewing individuals, particularly children, within the context of their families and communities, and drawing on the strengths of these networks to facilitate a successful and expedient recovery is paramount (Landau et al., 2008; Walsh, 2007). Feelings of insecurity, helplessness and meaninglessness are lessened when young people seek comfort and form strong connections with others that they can trust (Walsh, 2007). This trust and comfort is best placed within the community, because, unlike transient practitioners, these relationships are more likely to persist.

It is also very important for practitioners to remember that despite the trauma, challenges and adversity faced by people after an event such as this, some individuals experience positive and profound changes in their lives. Increased maturity, compassion, resilience, spirituality and appreciation of life are often reported in the months and years after facing and overcoming this type of adversity (Tedeschi \& Calhoun, 2004).

Moving away from my observations of coping within one flood-affected community, I would now like to share with you the articles presented in this edition of Children Australia. We begin with an Editorial Consultant commentary by Sandra Taylor and Aileen Ashford, who discuss the absence of young people's opinions in public forums that address issues of child protection. With particular reference to the recent Tasmanian Parliamentary Inquiry, they emphasise the importance of including young people's opinions when examining child protection policy and practice. Quite reasonably, Sandra and Eileen ask why young people's voices are excluded from such discussions, and what changes need to be made within decision-making processes to include young people's experiences and opinions.

The second piece is a practice-based commentary by Michelle VanDoorn and Marilyn Connolly who share their experiences of implementing 'The Circle Program' into their service at Ozchild. The Circle Program is best described as a therapeutic program that attends to children's emotional, psychological, behavioural and social responses to trauma, within an out-of-home care environment. Michelle and Marilyn report on the program's effectiveness at enhancing caregiver's capacity to provide children with a healing experience, and discuss the characteristics they found to be most conducive to quality care.

The commentaries are followed by a selection of articles that examine various aspects of coping. We begin with an overview of coping literature, prepared by Hannah Nikkerud and Erica Frydenberg. This detailed review contextualises the literature for the subsequent articles, as well as introducing the Adolescent Coping scale (ACS) as a measurement tool used by many of the articles that follow.

The second article, written by Kirsten Chalmers, Erica Frydenberg and Jan Deans, is an interesting study of preschool children's coping strategies and abilities. The authors found that, when presented with challenging scenarios, preschool children were competent at communicating a range of productive and nonproductive coping styles that they were likely to employ. Consequently, the authors advocate for productive coping strategy training to be incorporated into early school curriculums to help young people manage the challenges they will face throughout life.

The details of how coping strategies and styles are developed and nurtured are important precursors to the future development of these strategies. Hannah Nikkerud and Erica Frydenberg sought clarification about early influences on coping styles by comparing adolescent coping strategies with that of their same-sex parent. Using the ACS to measure participant coping strategies, significant differences were found between parents and adolescents. The authors concluded that adolescents do not imitate their parents' coping strategies, and that age and gender are better predictors of coping styles.

Coping strategies are an important part of wellbeing in general, but are particularly important for groups of 
young people who encounter daily challenges that place them at greater risk of developing psychological disorders. The following three articles have investigated coping strategies within specific groups of young people. Identifying a gap in the literature, Kerry Robertson and Erica Frydenberg studied the coping strategies employed by young people with high-functioning autism spectrum disorders. Their participants reported the use of multiple coping strategies, but often found these to be nonproductive and ineffective. The authors pointed to the value of further research as well as possible intervention for this group of young people.

Anna Serlachius, Erica Frydenberg, Elisabeth Northam and Fergus Cameron used the ACS to identify the coping strategies employed by young people with Type 1 diabetes. This group of young people were found to use a host of both productive and nonproductive coping strategies to help manage their illness. As with the earlier studies, the authors consider the benefits of teaching these young people effective ways of coping to help them better manage their illness and associated challenges.

The final article addressing the issue of coping is provided by Wan Hua Sim and Erica Frydenberg. Their study explores stress-related growth by siblings of children with special needs. The authors have provided an insightful and interesting account of the positive changes that siblings can experience after stressful events. This article offers a positive account of families' abilities to promote stress-related growth among siblings of children with special needs, as well as advocating for their own special needs of coping and problem-solving in what can be difficult circumstances.

This edition also includes a timely and valued contribution by Frank Ainsworth and Patricia Hansen who have provided a review and commentary of the recently released Munro Report. The Munro report is an independent review of the English child protection system. Frank and Patricia outline Munro's principles of effective and responsible child protection, as well as her recommendations for future policy and practice. The authors cite these principles and recommendations while drawing us into a comparison of Australian policy and practice with thought-provoking questions. In the wake of Munro's UK report, the Victorian government has released their new operating model entitled 'Protecting Children, Changing Lives: Supporting The Child Protection Workforce'. This model is designed to provide greater support to child protection practitioners, resulting in what they hope will be better outcomes for children, young people and their fam- ilies. Hopefully these documents will provide intellectual nourishment, as well as improved services for young people within the child protection system.

This edition concludes with a book review by Frank Ainsworth, who reports on Helping birth families. Services, costs and outcomes, written by Elsbeth Neil, Jeanette Cossar, Paula Lorgelly and Julie Young. In his review, Frank reports on the core themes of the book including birth relatives' experiences of compulsory adoption, the emotional and mental health of birth relatives, as well as an evaluation of support services offered to birth family relatives.

I hope that you find this edition informative, interesting and useful for service provision. Together with Jennifer, I would like to conclude this editorial with a special thank you to Associate Professor Erica Frydenberg for the remarkable contribution she has made to this issue with her colleagues. I would also like to send our congratulations to Freda Briggs AO for her recently published book Smart Parenting for Safer Kids, which she describes as a practical, explicit and realistic guide for handling parenting issues in contemporary western society.

\section{References}

Caruana, C. (2010). Picking up the pieces: family functioning in the aftermath of natural disaster. Family Matters, 84, 79-88.

Cook, A., Watson, J., van Buynder, P., Robertson, A., \& Weinstein, P. (2008). 10th anniversary review: Natural disasters and their long-term impacts on the health of communities. Journal of Environmental Monitoring, 10, $167-175$.

Landau, J., Mittal, M., \& Wieling, E. (2008). Linking human systems: Strengthening individuals, families and communities in the wake of mass trauma. Journal of Marital and Family Therapy, 34(2), 193-209.

MacDonald, E. (2009). Mental health needs post-disaster: Supporting recovery of children and families. Australian Occupational Therapy Journal, 56(2), 79-80.

Owen, L. (2005). Reflections on the past 30 years. Children Australia, 30(2), 3-10.

Tedeschi, R., \& Calhoun, L. (2004). Post-traumatic growth: Conceptual foundations and empirical evidence. Psychological Inquiry, 15, 1-18.

Walsh, F. (2007). Traumatic loss and major disasters: Strengthening family and community resilience. Family Process, 46(2), 207-227.

Rachael Sanders

\section{Children Australia acknowledges National Children's Week 22 to 30 October 2011, which includes Universal Children's Day held on Wednesday 26 October, 2011. For information on events celebrating Children's Week see: http://www.childrensweek.org.au/}

